\title{
Simulation Study on Flexibilities in the Material and Energy Flows of an Open-pit Mine
}

\author{
J ohannes Stoldt ${ }^{1 *}$, Christin Fanghänel ${ }^{1}$, Hans Rüdiger Lange ${ }^{2}$, Andreas Schlegel ${ }^{1}$, Thomas \\ Woldt ${ }^{3}$, Matthias Putz ${ }^{1}$
}

\author{
${ }^{1}$ Fraunhofer Institute for Machine Tools and Forming Technology IWU, Reichenhainer Strasse 88, 09126 Chemnitz, \\ Germany; *johannes.stoldt@iwu.fraunhofer.de \\ IInnovationsregion Lausitz GmbH, Goethestraße 1, 03046 Cottbus, Germany \\ ${ }^{3}$ Vattenfall Europe Generation AG, Vom-Stein-Straße 39, 03050 Cottbus, Germany
}

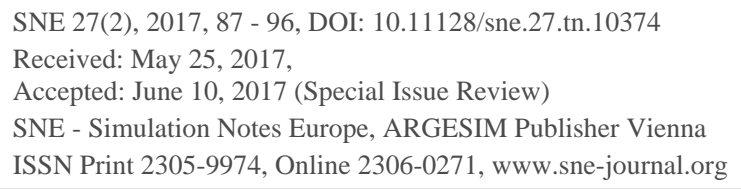

Abstract. The progressing introduction of renewable energy sources (RES) in the energy system creates an increasingly difficult market environment for traditional utility companies. While their fossil-fueled power plants are important to secure the supply of electricity, the associated operations are costly and energy intensive.

This paper presents a simulation study on an open-pit mine (OPM), where flexibilities are sought for increasing the operator's overall energy efficiency. For this purpose, the OPM's material flows and energy flows are simulated simultaneously. Drawing from discrete production systems in a "cross-learning" approach possibilities for and adjustments to the process control are investigated. Preliminary results show that some opportunities to increase efficiency exist but still require more scrutiny.

\section{I ntroduction}

Climate change as well as rising prices for natural resources along with the limited availability of the latter prompted the EU to implement the "2020 climate and energy package." The intention of this piece of legislation is to drastically improve energy efficiency, increase the share of renewable energy sources (RES) and lower the emission of greenhouse gases [1]. Due to this package and other national political changes (e.g. Germany's nuclear power phase-out) the share of RES is steadily rising. Such changes bring about fundamental changes to the market, most importantly volatility in energy supply. Yet, in all of the $27 \mathrm{EU}$ member states together, lignite (coal) is still an important primary energy source with a share of about $1 / 10^{\text {th }}$ (as of 2012) [2].
This share is even greater in Germany $\left(\approx 1 / 4^{\text {th }}\right)$ and Greece $(\approx 1 / 2)$ [2]. These numbers show how significant lignite-fired power plants (LFPP) still are in energy systems which rely increasingly on RES. This is especially true in periods when the natural availability of RES is limited.

The lignite required for the LFPP is procured from energy intensive open-pit mines (OPM). This dependence and the associated costs are an important issue for OPM operators - traditional utility companies. Technical and physical efficiency potentials have been nearly exhausted by an ongoing process of incremental improvements. Thus, the next lever, which could be used, is the control over the interaction of individual elements in the LFPP-OPM-system. To this end, available and exploitable flexibilities have to be identified first.

Vattenfall has made a point of implementing various measures to increase flexibility in the production as well as the load management in their OPM operations [3]. Thus, the underlying knowledge of the system can serve as the starting point for further analysis.

By means of discrete event simulation (DES), the work presented in this paper aimed to identify and assess available flexibilities in a specific OPM. A premise to this work was that mining operations could be regarded as both suppliers and consumers in the energy system. Hence, time-related improvement measures were deemed the most promising in terms of improving costs and process quality.

In the following, the concept of the simulation study is discussed in detail. Section 2 introduces an analysis of the system and Section 3 presents the implementation of the DES model. Finally, an overview of considered indicators and executed experiments is provided. 


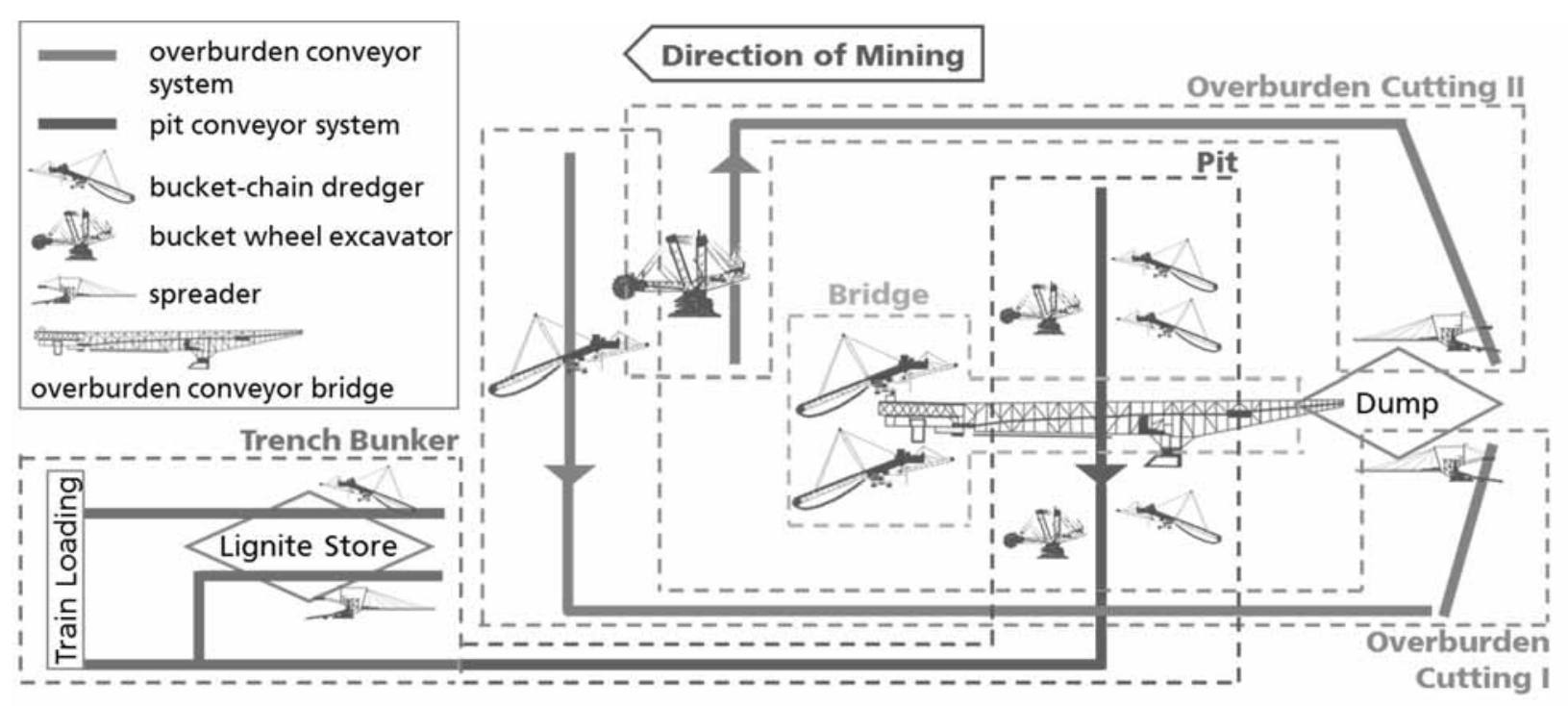

Figure 1: Layout and production process of Welzow-Süd open-pit mine.

\section{Concept of the Study}

DES was the enabler in this study to analyze the complex dynamics of the selected OPM using a deterministic model. In particular, the interrelations between various flexibilities and existing influences (e.g., personnel deployment, just-in-time lignite deliver, energy procurement, maintenance tasks, breakdowns, or weather risks) were to be evaluated. Eventually, the knowledge gained will serve to derive new control strategies for the OPM, which exploit available flexibility. Some previous papers discussed the use of DES for earthwork and mining processes as well as fleet management in such operations [4-7]. [8] reports on a simulation study in which a mining process was modelled mathematically but with little regard the short-term interactions of different pieces of equipment. A similar study with a greater focus on energy consumption is presented in [9]. The study presented here is new in that it regards the flow of material and energy in equipment over time in a single model.

Besides the possibility to also use probabilistic models in the future, DES was selected because an OPM can be likened, in many regards, to a clocked production line usually found in the automotive industry. For instance, most operating data is collected in a discretized manner so that the management view on the system is comparable (e.g. $\mathrm{m}^{3 / h}$ instead of units/h). Similarly, lignite can only be delivered if all prerequisites (e.g. functionality of all coupled machines as well as previous excavation of overburden) are fulfilled.
DES, to close again, is very well established for studies of automotive production systems. Coming from this likeness, a "cross-learning" approach between the automotive sector and the energy sector was followed. A fundamental research question was, if approaches proven successful in fostering energy efficiency in discrete production systems (e.g. [10,11]) could be applied in continuous systems. The tools of choice for this work were Siemens Tecnomatix Plant Simulation and Fraunhofer IWU's eniBRIC, a self-developed extension for the earlier (cf. Section 3.4).

\section{System Characterization}

For the purpose of this study, the OPM Welzow-Süd in Brandenburg, Germany, was selected. The following sections present the production process of this site as well as an overview on its utilization of energy.

\subsection{Lignite production in Welzow-Süd}

Like most OPMs, Welzow-Süd primarily utilizes continuous equipment technology. Matter above the lignite, so called overburden, is removed in three subsequent levels, loaded onto belt conveyors and transported to the other side of the excavation where it is dumped again [12] (cf. Figure 1). Once direct access is possible, lignite is excavated and transported either to the trench bunker for later loading or immediately to the train loading bays [12]. The OPM's progress, i.e. the direction of mining, is determined by prior geological analyses. 
For each ton of lignite extracted from Welzow-Süd approx. $6 \mathrm{~m}^{3}$ of overburden need to be moved. According to the ratio of about $6 \mathrm{~m}^{3}$ per ton, $110 \mathrm{Mm}^{3}$ of overburden a year are moved to produce $20 \mathrm{Mt}$ of lignite.

The direct dump system used for the third and last layer of overburden (cf. [12]; see middle of Figure 1) is a particularity of the Welzow-Süd OPM. It uses an overburden conveyor bridge to transport excavated matter to the opposite side of the pit in a highly performant and cost efficient manner. In order to exploit this potential to the fullest, the maximization of the bridge group's (bridge and two bucket-chain dredgers) utilization is a primary aim during operation.

Previous layers of overburden are removed by the overburden cutting groups I and II, respectively. Each of these consists of a bucket chain dredger or a bucket wheel excavator, a series of conveyors and a spreader. The latter is responsible for dumping the overburden evenly.

Two bucket wheel excavators along with three bucket chain dredgers mine the lignite in the pit. These machines feed onto a single line of belt conveyors and, thus, are operated selectively according to the quality of the coal found in the seam. Hence, only lignite of constant quality is transported to the trench bunker at any given time. Concurrent mining of different qualities is strictly avoided so that some excavators will need to pause.

Lignite from the pit will either be loaded onto trains immediately or stored on different heaps (sorted according to the quality) in the trench bunker for later loading. In total, up to $170.000 \mathrm{t}$ of lignite can be stored and, to maintain security of supply, a minimum of $90.000 \mathrm{t}$ should never be undercut. As trains are loaded throughout the week but the OPM only operated on business days, all loading on the weekend will drain the lignite heaps. In case the operating pit cannot keep up with the demand, trains will also be loaded from the bunker.

Each of the groups of equipment, i.e. each production area, can be regarded as a largely independent production line. These are operated predominantly independent from one another, which manifests, for instance, in the different shift schedules they have. Yet, a number of restrictions between the various areas exist. Generally speaking, overburden I maintains a minimum lead on overburden II, which maintains a lead on the bridge group, which maintains a lead on the pit. The bridge group, in particular, prioritizes specific areas under which lignite of a certain quality resides, based on demand estimations and the store development.
Keeping these restrictions in mind, some flexibility exists in the way lignite is exposed. Particularly the areas overburden I and II may prove useful in this regard. However, this potential is not used at this point because operators prefer to maximize the operation time of equipment. The rational therein is that future losses from equipment failures (or similar interruptions) need to be mitigated in advance.

An analysis of the equipment utilization statistics of the dredger as well as the excavator in the overburden cutting groups shows promise for load management approaches. Planned stops currently account for up to $20 \%$ of the overall production time. Load management approaches, such as those investigated for car body shops (e.g. [13, 14]), may be suitable to improve the energy efficiency in operation. The following list summarizes some previously identified mechanisms suited for this purpose and their respective characteristics:

- Quick shutdown: high impact, immediate effect, disrupting operation

- Modulation of production efforts: low impact, immediate effect, currently only manually, dependent on the current operating state

- Controlled ramp up/down: significant impact, reaction time approx. 30 minutes

- Shift rescheduling: long lead times required

\subsection{An OPM's role in the energy market}

Annually, Welzow-Süd usually consumes between 300 and $350 \mathrm{GWh}$ of electricity. The overburden cutting areas account for half of that, with another $30 \%$ being used by the bridge group and some $20 \%$ by the pit, the trench bunker and indirect areas (e.g. surface drainage). An exemplary overview of some system elements or areas is provided in Table 1 (average hourly consumption of active equipment during production).

Besides the operating time, the geology of the OPM has a major influence on the energy and material flows. The properties of excavated matter - e.g., humidity, density, etc. - influence both mining and transport processes. Accordingly, adjustments to the process parameters, such as the conveying speed, may be a necessary corrective action during operation. Consequently, the material flow intensity and the energy demand would change. Correlations of a similar kind can also be found for other equipment in the system. 


\begin{tabular}{ll}
\hline Elements (selection) & $\begin{array}{l}ø \text {-electricity } \\
\text { consumption } \\
\text { [MWh per } \mathrm{h}]\end{array}$ \\
\hline Bucket wheel excavator (OC II) & 3.7 \\
\hline Overburden conveyor (OC II) & 13.77 \\
\hline Spreader (OC II) & 2.71 \\
\hline Bucket-chain dredger & 4.31 \\
\hline Overburden conveyer bridge & 8.04 \\
\hline Bucket wheel excavator (pit) & 0.9 \\
\hline
\end{tabular}

Table 1: Hourly electricity consumption.

Just considering the conveyors, their energy consumption is dependent on the currently transported mass, the conveying speed, the length and the gradients of the various belt sections. In normal operation, especially the mass is the predominant influence, which causes variable load profiles. During ramp up and ramp down (when the conveyer fills up or empties), this effect is especially high. Inhomogeneity of the excavated matter will also have an effect. The conveyor layout changes less frequently, usually when significant progress in the direction of mining was made. In case of the overburden conveyor belts, a length of up to $14 \mathrm{~km}$ is possible and those linking the pit to the trench bunker may climb up to $80 \mathrm{~m}$ high.

Following the above remarks, it is evident that an OPM is a significant consumer in the energy markets. At the same time, it serves as a primary source for LFPP, which generates about a quarter of Germany's overall electricity supply. This double role and the fact that both OPM and LFPP are operated by the same company, pose a dilemma. When electricity is scarce, the electricity prices as well as the demand for lignite can be expected to rise. This, again, prompts for greater production of lignite and reduced energy demand from the OPM at the same time. The latter would decrease the (internal) energy costs of the mining operation. Furthermore, released capacity could be offered to external customers at a high price.

Four fundamental energy market mechanisms currently exist for planning and marketing the energy demand in advance or for reacting to fluctuations on a short-term basis. These influence, how flexibilities in an OPM could be exploited in a value-adding way. From long-term to short-term they are:
- Day-ahead marketing: lead time > $12 \mathrm{~h}$; solvent market; hourly products

- Intraday trading: lead time down to $1 \mathrm{~h}$ and under; quarter-hourly products

- Imbalance energy: minimization of volume delta reduces costs for balancing energy; ongoing with a quarter-hourly horizon

- Operating reserve: pre-qualifying; provision (binding); detailed regulation; requirements of technical controllability to meet dynamic control demand

The OPM's double role can also be contemplated from a sustainability angle. In this respect, it can be stated that the eco-efficiency of lignite production can be increased when times with high availability of RES are favored. Yet, this would increase the output when the LFPP's demand is actually waning.

To find the best course of action, the most appropriate operation strategies to follow in this complex environment, simultaneous simulation of the flows of material and energy was deemed the most promising approach. In particular, the most effective levers for exploiting available flexibilities in the mining process needed to be determined and their effects quantified.

\section{Simulation Model}

Once the scope of the project as well as its goals were clearly defined, the procedure model presented in the standard VDI 3633 Part 1 [15] was followed for to perform the simulation study. The following sections present the main results up to the mode implementation.

\subsection{System borders and level of abstraction}

Given the complexity of the system the definition of system borders was of great importance. These define which elements and flows should be simulated as well as where information, material, etc. needs to be exchanged with the environment. For the study of Welzow-Süd only those elements which have a part in the flows of lignite, overburden or electric energy were considered. This includes the geologic profile, excavators/dredgers, conveyors, spreaders and train loading. Indirect areas, such as revegetation, water management, etc. were dismissed as their energy demand and impact on operations was insignificant compared to that of the direct areas. 
While train loading marks the outbound border of the model, the demand of the LFPP was still considered. More specifically, the LFPP acted as a companyinternal customer, which generates production jobs for the OPM. These jobs, i.e. the demand for lignite, also translate into requirements regarding the removal of overburden.

Following the discussion in Section 2.2 it is evident that the structure of the lignite deposit and especially layers of matter above the seam have a tremendous effect on the energy consumption. Accordingly, the correlations between extracted matter (both lignite and overburden) and the production progress needed to be included in the model. Thus, the extraction sites demark the inbound border of the system. As modelling the actual geographical profile was considered too difficult and would have required excessive effort, they were abstracted to series of different types of matter.

The general level of abstraction for this study was defined to be equipment, i.e. excavators, conveyors, etc. Hence, the behavior of individual actors in the equipment was not considered in either the flow of materials or energy. Electricity sources and energy distribution equipment were disregarded, too.

\subsection{Data analysis}

In order to quantify and model the behavior of individual pieces of equipment and the system in general, an extensive analysis of pre-existing operating data was carried out. The basis for this work were production reports, production $\operatorname{logs}$, error $\operatorname{logs}$, train protocols, service protocols, energy consumption reports, etc. In effect, a realistic picture of the OPM could be obtained.

Yet, the available data were provided in inconsistent resolutions, sometimes using varying units of measurement, from different sources for the various system elements. To accommodate for the apparent differences, in-depth analysis and substantial pre-processing had to be performed.

Special emphasis was put on the identification of energy-related operating states and their respective electricity consumption behavior. The results thereof showed that between three to five operating states suffice to model the various pieces of equipment. These are generally "off", "disrupted" and "operational". In addition to these, selected pieces also have "moving", "switching cutting setup" (from above to below or vice versa), "start-up" or "overburden cutting" (as opposed to lignite cutting for excavators in the pit).
Especially the operational state but also the start-up state are related to the excavated or transported matter. The underlying correlations were also determined in the data analysis and described using simple linear regression curves. This type of regression was used as it yielded a high coefficient of determination for the analyzed data. On the one hand, other tested regression functions did not improve the accuracy considerably and, on the other hand, a simplified consumption model was preferred. The reason for the latter was that the overall modelling approach is rather abstract so that regressions that are more complex would suggest a level of precision in the model that was never targeted.

The calculations for the determination of the regression curves for excavators were based on the time series of lignite and overburden and the electricity consumption profiles of individual pieces of equipment. While information on the excavated matter could be extracted from production logs of a reference period, the content of conveyors had to be reconstructed. This was possible by means of the excavator behavior, the production logs and the error logs. The coefficients of determination $\mathrm{R}^{2}$ for individual regression curves lay in the range of approx. 0.70 to 0.95 , depending on the type of input data that could be used (see before).

The production logs primarily consist of minutely data of how much matter of which type was excavated. Analysis showed that three fundamentally different types of both lignite and overburden, each, were processed in the OPM. Furthermore, the raw data varies greatly (due to technologic reasons), so 5-minute averages were used throughout the study. The error log holds information on the beginning and end of equipment disruptions as well as the respective reason.

Information from both logs was used to execute preliminary simulation runs, from which the content profiles of conveyors and spreaders could be discerned. These were then overlaid with the energy consumption profile to calculate the missing regression curves.

\subsection{Model implementation}

All system elements were modelled in a single frame (Plant Simulation sub model). To improve the recognition value of the model (Figure 2), the layout of the individual elements principally recreates that of the actual OPM. Since the excavation sites were only modelled as time series, their respective objects only use static symbols. 


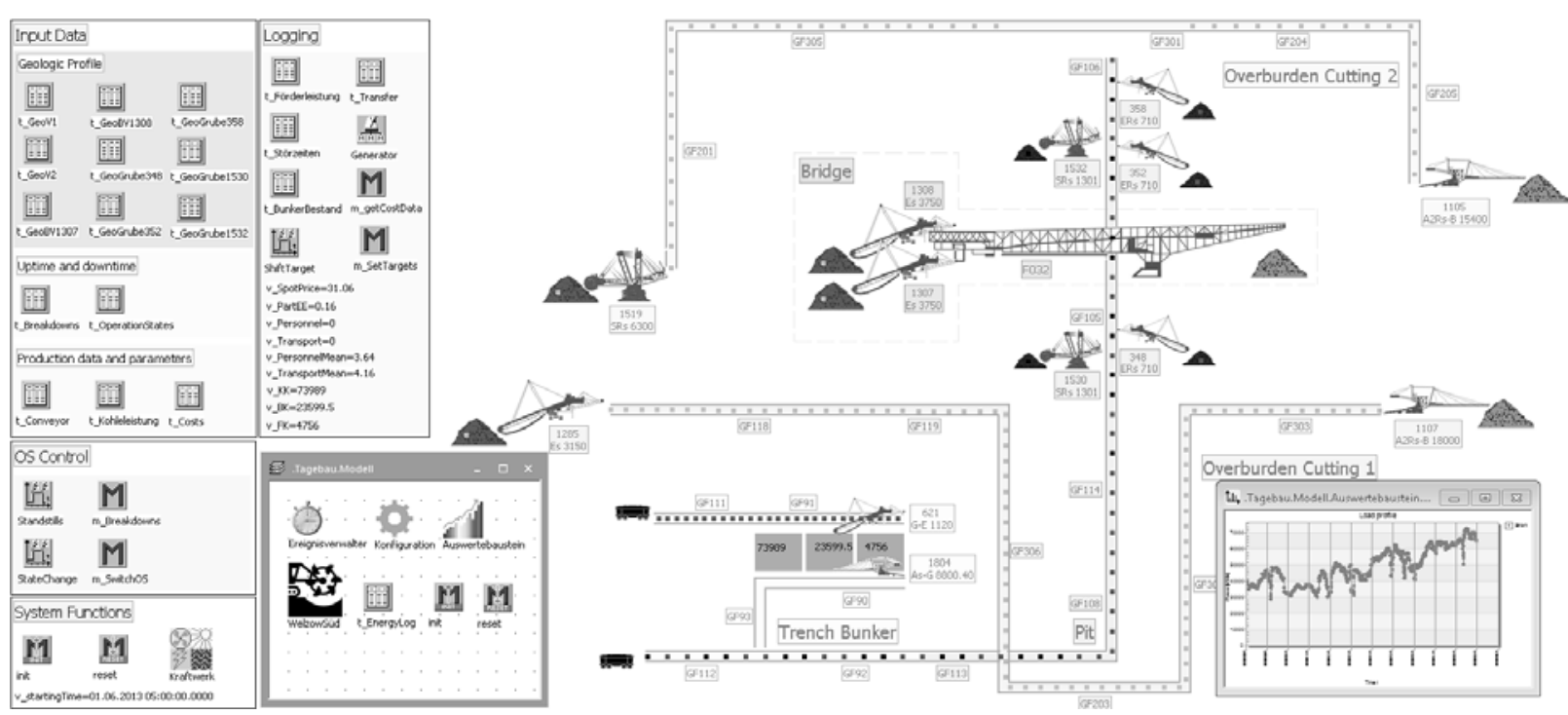

Figure 2: Screenshot of the simulation model with simulated load profile in lower right corner.

Hence, their progress is not reflected in the visualization during runtime. Similarly, the representation of other equipment changes neither in length/ shape (conveyors) nor in position (conveyors, excavators and spreaders) in accordance with the progress. Throughout the implementation, Plant Simulation's object-oriented modelling abilities have been utilized to reuse userdefined procedures and data structures. Accordingly, a basic class for matter (moveable unit; MU) was created, which contains specific attributes such as volume, power consumption, energy costs, etc. From this, lignite and overburden classes ( 3 of each) were derived. Upon instantiation by an excavation site (source) according to the predefined time series, they are initialized with specific attributes (e.g. volume of the 5-minute package). During simulation, other attributes are updated when necessary (cf. also Section 4.1).

Similarly, the excavators were based on a single excavator class, which is fundamentally a demounting station followed by a separation buffer (capacity 1, dwell time $30 \mathrm{~s}$ ). It receives 5-minute packages, splits them into 30-seconds packages (increasing the resolution for the energy demand calculation in following objects) and outputs one every $30 \mathrm{~s}$. Additionally, the excavator class includes the eniBRIC class to model the flow of energy (cf. Section 3.4). Derivatives of the base class have been created for selected groups of excavators according to the respective identified operating states. Thus, eniBRICs basic configuration could be preset specifically for these groups in the class library before the various excavators were instantiated.
The correct energy demand is set during runtime by means of user-defined procedures which are called when a new 5-minute package is processed.

Conveyors (including the bridge) and spreaders were also first implemented in a base class. Fundamentally, they are length-oriented conveyor objects (as opposed to the point-oriented objects used for excavators). In order to model the respective energy consumption, eniBRIC has been added as a sub class. During runtime, userdefined procedures calculate the conveyor content whenever it changes (MU entering/exiting) and then determine the new energy demand based on regression curves (cf. Section 3.2). The latter is then used to update the eniBRIC instance's current level of consumption. In the simulation model, the various conveyor sections, the bridge and the spreaders were instantiated and linked to one another as well as to the excavators (cf. Figure 2).

In addition to the elements of the material flow and the energy flow, the sequence logic was implemented in the model. It consists primarily of user-defined procedures and data/information objects. The latter are imported to the simulation upon model initialization and include, for instance, spot market prices, cost rates for personnel and transport, information on non-operating periods, lignite orders from the LFPP, etc. Once a simulation run commences, procedures are triggered based on these data to change the system elements' operating state according to the imported time series. Thus, breakdowns, shift breaks, etc. are simulated according to the available logs and protocols from the analyzed reference period (cf. Section 3.2). 
While this implementation was very well suited to validate the model conformity, prospective simulation experiments would require less deterministic sequence logic. Hence, the user-defined procedures were designed to also work with probabilistic inputs, e.g. for dealing with random equipment disruptions.

\subsection{Integration of eniBRIC}

While Plant Simulation versions 11 and onward provide basic functionality for simulating the flow of energy, these are arguably limited unless extended through userdefined procedures. The eniBRIC library (cf. [16,17]), on the other hand, was developed to be flexibly applied regardless the number of operating states or considered energy carriers.

As described in the previous section, one instance of eniBRIC is created for each instance of a material flow element. The respective configurations consist of the three to five operating states identified in the data analysis. For each of these, a specific demand was specified, as was the ability to realize a material flow in the respective state.

The consumption of excavators, conveyors and spreaders were determined to be variable, depending on the properties of excavated or transported matter. Hence, the operational state of the corresponding elements has been duplicated (e.g. operational 1 and 2) to be able to switch between different states that allow material to be processed. This was necessary to accommodate for eniBRIC's inherent control logic and was controlled via procedures that are called when the element contents change.

Within the model, only electricity was regarded. Since eniBRIC requires a source of energy for each energy carrier parameterized, an electricity source had to be instantiated. In the context of this model, this could be considered the connection to the utilities. Energy sources are, in essence, regular eniBRIC instances without additional material flow objects. During simulation, energy drains (i.e. material flow equipment) retrieve the location of the respective source from a preconfigured matrix in eniBRIC's configuration module.

Data collection and visualization during runtime is made possible by means of the evaluation module. It gathers information of the energy-related operating state transitions and the corresponding energy demand profiles. Most in-depth analysis for the experiments presented in Section 4.2, however, were performed on data exported from this module's instance in the model.

\subsection{Model tuning, verification and validation}

As mentioned before, the entire system was modelled based on data provided for a reference period (1 month). To verify the model's general correctness and validate its fundamental ability to study available flexibilities, the models performance was compared to that of the actual system. In particular, the variance and the cumulated error of the system output indicators as well as the energy consumption profiles were checked.

Figure 3 depicts an exemplary graph, which was used to visually ascertain the variance between reality and model. Similar comparisons have been made for the entire system, other areas of the OPM (e.g. overburden cutting I, etc.) and even individual pieces of equipment.

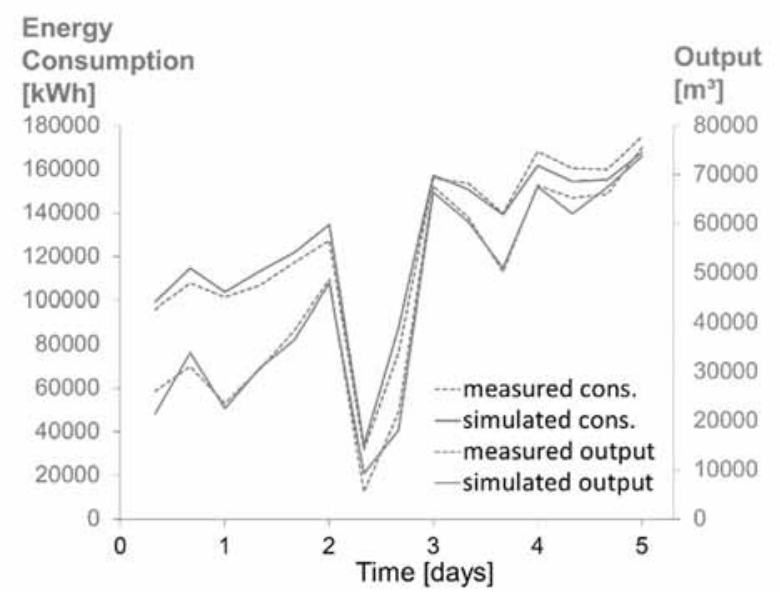

Figure 3: Comparison of energy consumption [kWh] and output $\left[\mathrm{m}^{3}\right]$ for overburden cutting II.

Initial results showed some more divergence between the real system's behavior and the model. Further tweaks of the model parameterization were then applied in an iterative process in order to refine the results considerably.

A typical verification and validation procedure as proposed in state of the art literature (e. g. [15]) was applied to the model with its eventual parameterization. The final variance of the entire system's energy consumption, volume of moved overburden and lignite production was eventually determined to be $\approx 0.3 \%$, $\approx 0.0 \%$ and $\approx 1.1 \%$, respectively. Similarly, the cumulated errors for these indicators were determined to be $\approx 0.7 \%, \approx 0.8 \%$ and $\approx 0.6 \%$. 


\section{Simulation Experiments and Results}

The previous section illustrated how a valid model of the OPM was created. It was used for first simulation experiments in order to identify exploitable flexibilities. To ascertain these accurately, various indicators were defined, which are described in the following section. Afterwards, some preliminary results are presented.

\subsection{Relevant indicators}

In order to investigate, for example, flexibilities in the electricity market or in the lignite demand several global indicators were defined. Particularly, the following were determined to be of interest:

- Variance of the electricity price from the average,

- Primary energy factor of consumed electricity based on the German electricity mix,

- Deviation of targeted to actual output of lignite,

- Utilization of lignite production capacity, and

- Variance of costs for personnel and transportation.

Other possible indicators can be, for instance, the share of electricity costs on the overall operating costs, the distribution of specific energy costs (over time or overhead/lignite) or the utilization ratio of the trench bunker. To provide the necessary inputs for computing any of these indicators, both real data, which are partly input information of the model, and simulation data are combined. The resulting time series of indicators mark the starting point for the analysis of potentially influenceable production processes and related effects resulting from their exploitation.

In addition to the above indicators, the simulation model can generate statistics for each processed volume package. This includes the following specific indicators:
- Time of extraction,

- Specific personnel and transport costs,

- Specific throughput time,

- Specific power consumption,

- Specific energy costs, and

- Specific primary energy utilization.

At the time of a package's creation in the simulation, the time of extraction as well as personnel and transport costs (as products of the package's tonnage and specific cost rates) are determined. The specific throughput time is calculated when packages leave the system and may be used as pointers to identify process disturbances. The specific power consumption refers to a single volume package. It is calculated considering the volumedependent power demand of the different system elements (cf. Section 3.3).

Accordingly, the relevant attribute of an MU is updated whenever the energy consumption of a material flow object changes or the MU exits one of the former. The specific energy costs and the primary energy utilization are based on the specific power consumption and, thus, are updated in the same manner. They are calculated by multiplying the specific consumption with the spot market prices and the percentage of non-renewably sourced electricity, respectively. Both scalars were regarded as time-dependent.

\subsection{Discussion of experiments}

Multiple simulation experiments were performed to identify available flexibilities. These generated different data sets for the global indicators as well as for the specific indicators. The experimental design followed an expert-knowledge-driven approach, where input information was varied in accordance with suggestions from the project team.
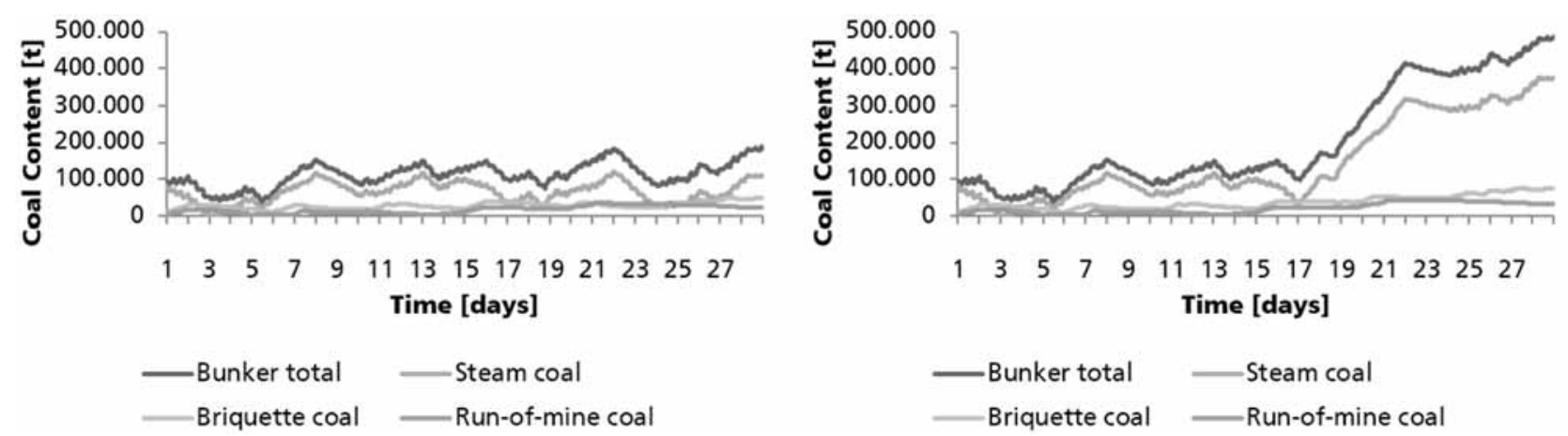

Figure 4: Trench bunker content in reference scenario (status quo; left) and with reduced lignite demand of LFPP (right) over time. 
Thus, a number of distinct scenarios were defined. Deterministic simulation runs were performed for these and analyzed qualitatively as well as quantitatively. Examples for such experiments are:

- Altered electricity price curve,

- Reduction of lignite demand, and

- Reduced frequency of breakdowns.

An altered electricity price curve directly affects the energy costs of the production system. The amplitude of this change is quite significant. It is therefore important that the results are analyzed to derive more costefficient operation strategies. The scenario 'reduction of lignite demand' investigates, for example, how an unplanned increase in production of renewable energy sources influences the system. A change like this would diminish the demand for electricity generation at the LFPP and, thus, delay the latter's orders for lignite. In such a case, the trench bunker starts to fill up to its capacity if production continues unchanged. Figure 4 depicts the content of the trench bunker for the status quo (reference scenario) as well as for the demand reduction scenario, as simulated. On the other hand, the energy mix in this time is environmentally friendly due to reduced reliance on fossil fuels. Accordingly, operation strategies should be defined to balance the trench bunkers content and the company's economic, as well as ecologic targets. The approach presented in [18] may serve as a starting point for this.

Decreasing production or shifting it - preferably to periods which promise greater energy efficiency - are possible courses of action to prevent excessive stocking of lignite. These require stable processes, i.e. a reduced number and total length of breakdowns, to ensure that operation is possible when intended. For both decreasing and shifting production, the determination of thresholds for controlling the OPM processes is a necessity. The simulation results of the scenario 'Reduced frequency of breakdowns' provided initial insights on this. Furthermore, greater energy efficiency from the company's point of view in this context can mean either less primary energy per ton of lignite or more profit in marketing LFPP capacity. In the latter, the OPM operation would be shifted to times of lower electricity prices or make use of demand response to sell the generated energy at the highest price possible.

These above experiments were performed and results are currently analyzed by mining experts. Their eventual goal is to identify exploitable flexibilities and define strategies to optimize the process control accordingly. Especially plan revisions during the day and short-term load reductions are promising because they may allow for intraday trading at the spot markets. Improvements on the input data and additional experiments are planned to investigate this more thoroughly in the future.

\section{Conclusion}

Lignite-fired power plants (LFPP) along with open-pit mines (OPM) are the backbone of many national energy systems. In Germany, around $1 / 4^{\text {th }}$ of the electricity is sourced from LFPPs. As OPMs are very energy intensive, operators aim to improve their energy efficiency. For this purpose, the here-presented study applied a "cross-learning" approach to identify suitable flexibilities by likening the OPM to a discrete production system (e.g. a car body production line). It was modelled using Plant Simulation and eniBRIC (a self-developed extension to the earlier) to simulate both the material flow and the energy flow simultaneously.

Initially, the prime targets of the simulation study and the system borders have been defined. Subsequently, an in-depth data analysis based on real data from the OPM Welzow-Süd was performed. The results thereof went into parameterizing the model. During the implementation, all continuous flows of matter were discretized over time, i.e. equidistant volume packages of varying size. The energy demand of the regarded system elements was modelled as either operating state averages or using regression curves. After successful validation of the deterministic model, initial experiments were designed and performed.

Preliminary results showed how the system behaves when operation conditions change, particularly when renewable sources suddenly provide excess energy. Further experiments showed how adjustments in the operation schedules of equipment (e.g. by reducing failure times) would affect the system's main performance indicators.

All of these results are currently being scrutinized by mining experts to identify suitable approaches for exploiting identified flexibilities. The results of this work will need to be tested in the simulation model. Applying probabilistic parameterizations to simulate machine failures and extraction rates may also allow for assisting simulations during the operation phase. 


\section{References}

[1] European Commission. The 2020 climate and energy package. http://ec.europa.eu/clima/policies/strategies/ 2020/index_en.htm [Acc. 07-06-2016].

[2] EUROCOAL. The Role of Coal for Power Generation in Europe 2012. 2014, URL:

http://euracoal2.org/download/PublicArchive/Library/Charts-Maps/Electricity-inEurope/Strom-Kohle-2012-EN.pdf [Acc. 07-06-2016].

[3] Lange HR, Woldt T, Köhler U. Von ,just in time“ zu ,just to energy“? Ein Praxisbericht zur Integration von Last- und Erzeugungsmanagement im industriellen Maßstab (Bergbau). In Institutskolloquium am Institut für Industriebetriebslehre und industrielle Produktion (IIP); 2014; Karlsruhe.

[4] Basu AJ, Baafi EY. Discrete event simulation of mining systems: Current practice in Australia. Int. J. of Surface Mining, Reclamation and Environment. 1999; 13(2): 79 84. doi: 10.1080/09208119908944214

[5] Ji Y, Borrmann A, Wimmer J, Günthner WA. Bidirectional Coupling of Macroscopic Optimization and Microscopic Simulation of Earthwork Processes. In 27th Conference on Applications of IT in the AEC Industry. 2010.

[6] Hashemi AS, Sattarvand J. Simulation Based Investigation of Different Fleet Management Paradigms in Open Pit Mines-A Case Study of Sungun Copper Mine. Archives of Mining Sciences. 2015; 60(1): 195-208. doi: 10.1515/amsc-2015-0013

[7] ANDRITZ Automation. IDEAS: Steady-state solutions for mining operations. https://www.andritz.com/aasteadystate-simulation-mining.pdf [Acc. 11-10-2016].

[8] Ayman Abdelfattah Mahmoud A. Development of an Integrated Mining and Processing Optimization System [dissertation]. Technische Universität Bergakademie Freiberg; 2013.

[9] Li L, Zheng Y, Zhu K. Simulation of the Energy Saving and Emission Reduction in Coal Mine Areas Based on System Dynamics. International Journal of Nonlinear Science. 2011; 12(1): 117-122.

[10] Langer T, Schlegel A, Stoldt J, Putz M. A Model-based Approach to Energy-saving Manufacturing Control Strategies. Procedia CIRP. 2014; 15: 123-128. doi: 10.1016/j.procir.2014.06.019
[11] Duflou JR, Sutherland JW, Dornfeld D, Herrmann C, Jeswiet J, Kara S, Hauschild M, Kellens K. Towards energy and resource efficient manufacturing: A processes and systems approach. CIRP Annals Manufacturing Technology. 2012; 61(II):587-609. doi: 10.1016/j.cirp.2012.05.002

[12] Stoll RD, Niemann-Delius C, Drebenstedt C, Müllensiefen K, editors. Der Braunkohletagebau - Bedeutung, Planung, Betrieb, Technik, Umwelt. Berlin, Heidelberg: Springer; 2009. 605 p.

[13] Knafla F, Richter M. Einfach mal abschalten - Karosseriebau: Effizienter produzieren. IEE. 2013; 58(5): 66-68.

[14] Wolff D, Hundt L, Dreher S. Requirements on the Engineering of Advanced Standby Strategies in Automobile Production. In: Seliger G, editor. Proc. of the 11th Global Conference on Sustainable Manufacturing (GCSM) Innovative Solutions; 2013 Sep, Berlin. Berlin: Universitätsverlag der TU Berlin. 171-176.

[15] VDI-Gesellschaft Produktion und Logistik (GPL). VDI 3633, Part 1: Simulation of Systems in materials handling, logistics and production-Fundamentals. Berlin, Beuth, 2014. 48 p.

[16] Stoldt J, Schlegel A, Franz E, Langer T, Putz M. (2013). Generic Energy-Enhancement Module for Consumption Analysis of Manufacturing Processes in Discrete Event Simulation. In A. Y. C. Nee, B. Song, \& S.-K. Ong, editors. Re-engineering Manufacturing for Sustainability. Proceedings of the 20th CIRP International Conference on Life Cycle Engineering; 2013 Apr; Singapore. Singapore: Springer Singapore. 165-170. doi: 10.1007/978981-4451-48-2_27

[17] Stoldt J, Schlegel A, Putz M. Enhanced integration of energy-related considerations in discrete event simulation for manufacturing applications. J. of Simulation. 2016; 10(2): 113-122. doi: 10.1057/jos.2015.24

[18] Putz M, Götze U, Stoldt J, Franz E. Target systems and Decicion-Making to Increase Production Sustainability. Procedia CIRP. 2016; 48: 34-39. doi: 10.1016/j.procir.2016.03.034 